\title{
PENGARUH FASILITAS BELAJAR TERHADAP MOTIVASI BELAJAR SISWA KELAS V DI SDN 001 SAMARINDA UTARA
}

\author{
Ratna Khairunnisa, Andi Aslindah, Aji Fitri Rahmadana \\ Universitas Widyagama Mahakam Samarinda \\ ratna@uwgm.ac.id, aji fitrirahmadana@yahoo.com
}

\begin{abstract}
ABSTRAK
Penelitian ini bertujuan untuk mengetahui pengaruh fasilitas belajar terhadap motivasi belajar siswa kelas V di SDN 001 Samarinda Utara Tahun Pembelajaran 2018/2019. Penelitian ini dilaksanakan pada tanggal 20 Maret - 02 April 2019. Penelitian ini dilakukan di SDN 001 Samarinda Utara. Sampel dalam penelitian ini adalah siswa dan siswi kelas V-A dan V-B SDN 001 Samarinda Utara. Penelitian ini menggunakan teknik pengumpulan data dengan angket dan dokumentasi. Teknik analisis data menggunakan analisis regresi linier sederhana.

Hasil dari penelitian ini menunjukkan bahwa: (1) terdapat pengaruh fasilitas belajar terhadap motivasi belajar siswa kelas V di SDN 001 Samarinda Utara, hal ini dibuktikan dengan ditolaknya $\mathrm{H0}$ dan diterimanya Ha yang diajukan karena nilai $r_{\text {hitung }}>r_{\text {tabel }}$ yaitu 0.325 $>0.268$ pada taraf signifikansi 5\% dengan jumlah responden $(\mathrm{N})$ sebanyak 54. (2) berdasarkan nilai $R$ Square yang diperoleh, maka besarnya pengaruh fasilitas belajar terhadap motivasi belajar siswa kelas V di SDN 001 Samarinda Utara yaitu sebesar 0,106 atau 10,6\%.
\end{abstract}

Kata Kunci: Fasilitas, Motivasi, Belajar

\section{ABSTRACT}

This study aims to know how learning facility influences students' learning motivation, especially for fifth grade students in SDN 001 Samarinda Utara. This study was conducted on $2^{\text {nd }}$ April 2019. The researcher involved 54 fifth graders of SDN 001 Samarinda Utara as the research subjects. Questionnaire and documentation were conducted for collecting the data. The data were then analyzed by using simple linear regression analysis.

The research result shows that; (1) learning facility significantly influences students' learning motivation, especially in class V of SDN 001 Samarinda Utara. The Null Hypothesis was rejected and the Alternative Hypothesis was accepted based on the value of $t_{\text {count }}>t_{\text {table; }}$; $0.325>0.268$ at $5 \%$ significant level. (2) Based on the value of $R$ square, learning facility influences learning motivation at 0.106 or about $10.6 \%$.

Keywords: Learning Facility, Learning Motivation

\section{PENDAHULUAN}

Tempat pertama bagi seorang anak untuk mendapatkan pendidikan adalah keluarga. Pendidikan ini diberikan oleh orang tua dan pendidikan tersebut dinamakan informal. Pada tahap pendidikan keluarga ini, orang tua sangat berperan penting karena orang tua adalah sekolah pertama bagi anak, dalam hal ini orang tua harus membimbing dan mengarahkan anak untuk mengenal sikapsikap baik seperti mengajarkan mengenai etika, sopan santun, maupun pengetahuan- pengetahuan lainnya. Selain mengajarkan ilmu pengetahuan, orang tua juga berperan sebagai fasilitator maupun motivator.

Orang tua memiliki kewajiban untuk memenuhi kebutuhan anak, selain kebutuhan hidup, anak juga membutuhkan ilmu pengetahuan. Untuk mendapatkan ilmu pengetahuan dibutuhkan sarana pendukung, seperti buku bacaan, buku tulis, alat tulis atau permainan yang dapat merangsang otak anak. Karena orang tua harus memberikan fasilitas yang baik untuk mempermudah anak memperoleh 
pengetahuan. Setelah fasilitas belajar anak terpenuhi, maka orang tua harus memberikan anak dorongan atau motivasi agar mereka selalu giat belajar serta menanamkan bagaimana pentingnya memiliki ilmu pengetahuan.

Setelah melalui tahap pendidikan informal, selanjutnya akan belajar pada pendidikan formal. Tempat mendapatkan pendidikan formal ini ialah sekolah. Sekolah merupakan tempat berlangsungnya kegiatan pendidikan. Sekolah merupakan tempat ke dua bagi anak, dan guru yang berada di sekolah berperan sebagai orang tua pengganti. Dengan demikian ketika siswa telah berada di lingkungan sekolah, maka mereka adalah tanggung jawab pihak sekolah. Karena itu siswa berhak mendapatkan pendidikan yang layak serta mendapat perlindungan.

Untuk menunjang berlangsungnya kegiatan pendidikan di sekolah, maka sekolah memerlukan sarana dan prasarana pendukung. Pemerintah pusat, pemerintah daerah sampai dengan organisasi penyelenggara satuan pendidikan harus selalu berupaya agar pendidikan dapat diselenggarakan dengan memiliki kualitas yang baik. Sebab peningkatan mutu pendidikan harus dilakukan secara terusmenerus. Salah satu cara untuk meningkatkan mutu pendidikan yaitu, tersedianya sarana dan prasarana pendidikan yang memadai. Sarana ini merupakan penunjang proses belajar mengajar.

Peranan sarana dan prasarana dalam pendidikan sangat dibutuhkan dengan adanya perkembangan zaman yang semakin canggih. Jika tidak menyesuaikan dengan perkembangan yang ada, maka proses kegiatan pembelajaran akan terhambat dan tertinggal dengan negara lain., oleh sebab itu sekolah perlu menyediakan sarana dan prasarana yang memadai. Semakin lengkap sarana dan prasarana yang ada di sekolah, maka semangat peserta didik pun akan bertambah. Namun adanya sarana dan prasarana yang memadai tidak berguna jika tidak dimanfaatkan dengan baik. Dengan adanya kelengkapan sarana dan prasarana belajar yang disediakan oleh pihak sekolah, maka semua warga yang ada di lingkungan sekolah harus menjaga sarana dan prasarana yang dimiliki.

Pentingnya sarana dan prasarana belajar yang harus dimiliki peserta didik bukan hanya pada saat di sekolah, siswa juga tetap membutuhkan fasilitas belajar pada saat di rumah. Hanya saja fasilitas yang tersedia di rumah adalah tanggung jawab orang tua atau keluarga. Setelah kebutuhan fasilitas belajar anak terpenuhi maka mereka akan semakin termotivasi untuk terus meraih prestasi.

Keberadaan fasilitas belajar sebagai penunjang kegiatan pembelajaran sangat berpengaruh terhadap hasil belajar serta prestasi siswa, ini karena fasilitas belajar dapat mempengaruhi kelancaran serta hasil belajar. Hal ini sesuai dengan pendapat Dalyono (2001) yang mengatakan bahwa: "Kelengkapan fasilitas belajar akan mambantu siswa dalam belajar dan kurangnya fasilitas belajar dapat menghambat kemajuan belajarnya". Selain itu menurut Arsyad (2013) pemanfaatan sarana belajar dapat memberikan manfaat untuk meningkatkan dan menggairahkan perhatian anak sehingga dapat menimbulkan motivasi belajar.

Dari teori yang mengatakan bahwa kelengkapan sarana belajar dapat menimbulkan motivasi belajar siswa dengan demikian penulis tertarik untuk melakukan penelitian dengan judul "Pengaruh Fasilitas Belajar terhadap Motivasi Belajar Siswa Kelas V di SDN 001 Samarinda Utara"

\section{Metode Penelitian}

Jenis penelitian ini merupakan penelitian kuantitatif. Populasi penelitian ini yaitu seluruh siswa SDN 001 Samarinda Utara dari kelas 1-6 yang berjumlah 347 siswa. Teknik penentuan sampel dalam penelitian ini menggunakan teknik Purposive Sampling, adapun sampel dalam penelitian ini yaitu siswa kelas VA (27 
Siswa) dan VB (27 Siswa) SDN 001 Samarinda Utara, dengan menggunakan teknik pengumpulan data berupa angket dan dokumentasi.

\section{Hasil Penelitian dan Pembahasan}

Berdasarkan hasil analisis dari persamaan regresi $\mathrm{Y}=56.554+0.369 \mathrm{X}$ diperoleh nilai fasilitas belajar terhadap motivasi belajar terbukti signifikan. Hal ini dibuktikan dengan hasil uji regresi linier sederhana dimana nilai $r_{\text {hitung }}>r_{\text {tabel }}$ yaitu $0.325>0.268$. Dari persamaan regresi ini juga diketahui apabila fasilitas belajar ditingkatkan sebesar 1\% maka motivasi belajar siswa akan meningkat sebesar 0.369 atau $36.9 \%$. Dalam penelitian ini didapatkan nilai $R$ Square sebesar 0.106 yang menunjukkan bahwa pengaruh fasilitas belajar terhadap motivasi belajar adalah 0.106 atau $10.6 \%$ dan tergolong masih sangat rendah.

Dengan demikian maka ada terdapat pengaruh fasilitas belajar terhadap motivasi belajar pada siswa kelas V di SDN 001 Samarinda Utara tahun pembelajaran 2018/2019. Fasilitas belajar merupakan salah satu hal yang dapat menumbuhkan motivasi belajar siswa, serta pentingnya keberadaan fasilitas belajar disekolah dapat mempermudah proses pembelajaran. Namun dalam penelitian ini pengaruh fasilitas belajar terhadap motivasi belajar siswa hanya sebesar $10.6 \%$ yaitu tergolong masih sangat rendah. Ini menunjukkan bahawa terdapat faktor lain yang lebih besar pengaruhnya terhadap motivasi belajar siswa di SDN 001 Samarinda Utara Dengan demikian hasil penelitian ini dapat mendukung teori yang telah dikemukakan oleh Arsyad (2013) bahwa pemanfaatan sarana belajar dapat memberikan manfaat untuk meningkatkan dan menggairahkan perhatian anak sehingga dapat menimbulkan motivasi. Hal ini karena penelitian ini menunjukkan bahwa nilai $R$ Square adalah sebesar 0.106 atau pengaruhnya sebesar $10.6 \%$.

Selain itu, penelitian ini juga sejalan dengan penelitian yang dilakukan oleh
Wahyuningrum (2015) yang menyimpulkan bahwa besarnya pengaruh fasilitas belajar di sekolah terhadap motivasi belajar siswa tergolong lemah dengan koefisien $\mathrm{R}$ sebesar 0.210 . Sedangkan kontribusi variabel $\mathrm{X}$ terhadap variabel Y sebesar $4.4 \%$ kemudian sisanya $95.6 \%$ ditentukan oleh faktor lain. Sementara besar kecilnya motivasi belajar siswa dapat diprediksi melalui persamaan regresi $\mathrm{Y}=59.995+0.168 \mathrm{X}$.

\section{Kesimpulan}

1. Ada pengaruh yang signifikan antara fasilitas belajar terhadap motivasi belajar siswa kelas V SDN 001 Samarinda Utara. Hal ini dibuktikan dengan ditolaknya $\mathrm{H} 0$ dan diterimanya Ha yang diajukan karena nilai $r_{\text {hitung }}>$ $r_{\text {tabel }}$ yaitu $0.325>0.268$ pada taraf signifikansi $5 \%$ dengan jumlah responden $(\mathrm{N})$ sebanyak 54 .

2. Berdasarkan nilai $R$ Square yang diperoleh maka besarnya pengaruh fasilitas belajar terhadap motivasi belajar siswa kelas V SDN 001 Samarinda Utara tergolong masih sangat rendah yaitu sebesar 0.106 atau $10.6 \%$.

3. Dari persamaan regresi diketahui nilai constant (a) 56.554 dan (b) 0.369 . sehingga dapat dinyataka apabila Fasilitas Belajar ditingkatkan sebesar $1 \%$ maka Motivasi Belajar siswa akan meningkat sebesar 0.369 atau $36.9 \%$. Sehingga dikatakan bahwa arah pengaruh variabel $\mathrm{X}$ terhadap $\mathrm{Y}$ adalah positif.

Dalam penelitian ini penulis hanya meneliti pengaruh fasilitas belajar terhadap motivasi belajar siswa kelas V di SDN 001 Samarinda Utara yang didapatkan hasil bahwa pengaruhnya hanya sebesar $10.6 \%$, yaitu tergolong masih sangat rendah. Oleh karena itu untuk peneliti selanjutnya diharapkan dapat mengembangkan kemungkinan adanya faktor lain seperti faktor lingkungan keluarga, lingkungan sekolah serta kreatifitas guru dalam 
mengajar yang lebih berpengaruh terhadap motivasi belajar yang tidak penulis teliti dalam penelitian ini.

\section{Daftar Pustaka}

Arikunto, S. (2013). Prosedur Penelitian Suatu Pendekatan Praktik. Jakarta: PT Rineka Cipta.

Arsyad, A. (2013). Media Pembelajaran. Jakarta: PT Raja Grafindo Persada.

Barnawi, \& Arifin, M. (2017). Sistem Penjamin Mutu Pendidikan Teori \& Praktik. Yogyakarta: Az-Ruzz Media.

Dalyono, M. (2001). Psikologi Pendidikan. Jakarta: Rineka Cipta.

Daryanto, \& Farid, M. (2013). Konsep Dasar Manajeman Pendidikan di Sekolah. (T. Marjuki, Ed.). Yogyakarta: Gava Media.

Djamarah, S. B. (2011). Psikologi Belajar. Jakarta: PT. Rineka Cipta.

Hamalik, O. (2011). Proses Belajar Mengajar. Jakarta: PT Bumi Aksara.

Hasan, I. (2010). Analisis Data Penelitian dengan Statistik. Jakarta: PT Bumi Aksara.

Kompri. (2016). Motivasi Pembelajaran Perspektif Guru dan Siswa. Bandung: PT Remaja Rosdakarya.

Mardianto. (2012). Psikologi Pendidikan Landasan Bagi Pengembangan Strategi Pembelajaran. Medan: Perdana Publishing.

Margono, S. (2004). Metodologi Penelitian Pendidikan. Jakarta: PT Rineka Cipta.

Matin, \& Fuad, N. (2016). Manajemen sarana dan Prasarana Pendidikan Konsep dan Aplikasinya. Jakarta: PT
RajaGrafindo Persada.

Mulyasa, E. (2014). Manajeman Berbasis Sekolah Konsep, Strategi, dan Implementasi. Bandung: PT Remaja Rosdakarya.

Mustari, M. (2015). Manajemen Pendidikan. Jakarta: PT RajaGrafindo Persada.

Priyanto, D. (2014). SPSS 22 Pengolah Data Terpraktis. Yogyakarta: Andi Offset.

Purwanto. (2015). Metodologi Penelitian Kuantitatif untuk Psikologi dan Pendidikan. Yogyakarta: Pustaka Pelajar.

Rahyubi, H. (2012). Teori-Teori Belajar dan Aplikasi Pembelajaran Motorik Deskripsi dan Tinjauan Kritis. Bandung: Nusa Media.

Sanjaya, W. (2009). Strategi Pembelajaran Berorientasi Standar Proses Pendidikan. Jakarta: Kencana Prenada Media.

Sardiman, A. (2018). Interaksi dan Motivasi Belajar Mengajar. Depok: PT RajaGrafindo Persada.

Siregar, S. (2017). Metode Penelitian Kuantitatif. Jakarta: Kencana.

Slameto. (2010). Belajar dan FaktorFaktor yang Mempengaruhinya. Jakarta: PT Rineka Cipta.

Sopiatun, P. (2010). Manajemen Belajar Berbasis Kepuasan Siswa. Jakarta: Ghalia Indonesia.

Sudarmanto, R. G. (2005). Analisis Regresi Linear Ganda dengan SPSS. Yogyakarta: Graha Ilmu.

Sugiyono. (2015). Metode Penelitian Pendidikan Pendekatan Kuantitatif, 
Kualitatif dan R\&D. Bandung: Alfabeta.

Sugiyono. (2016). Statistika untuk Penelitian. Bandung: Alfabeta.

Sujarweni, W. (2014). Metodologi Penelitian Lengkap, Praktis dan Mudah Dipahami. Yogyakarta: PT Pustaka Baru.

Arikunto, S. (2013). Prosedur Penelitian Suatu Pendekatan Praktik. Jakarta: PT Rineka Cipta.

Arsyad, A. (2013). Media Pembelajaran. Jakarta: PT Raja Grafindo Persada.

Barnawi, \& Arifin, M. (2017). Sistem Penjamin Mutu Pendidikan Teori \& Praktik. Yogyakarta: Az-Ruzz Media.

Dalyono, M. (2001). Psikologi Pendidikan. Jakarta: Rineka Cipta.

Daryanto, \& Farid, M. (2013). Konsep Dasar Manajeman Pendidikan di Sekolah. (T. Marjuki, Ed.). Yogyakarta: Gava Media.

Djamarah, S. B. (2011). Psikologi Belajar. Jakarta: PT. Rineka Cipta.

Hamalik, O. (2011). Proses Belajar Mengajar. Jakarta: PT Bumi Aksara.

Hasan, I. (2010). Analisis Data Penelitian dengan Statistik. Jakarta: PT Bumi Aksara.

Kompri. (2016). Motivasi Pembelajaran Perspektif Guru dan Siswa. Bandung: PT Remaja Rosdakarya.

Mardianto. (2012). Psikologi Pendidikan Landasan Bagi Pengembangan Strategi Pembelajaran. Medan: Perdana Publishing.

Margono, S. (2004). Metodologi Penelitian Pendidikan. Jakarta: PT Rineka
Cipta.

Matin, \& Fuad, N. (2016). Manajemen sarana dan Prasarana Pendidikan Konsep dan Aplikasinya. Jakarta: PT RajaGrafindo Persada.

Mulyasa, E. (2014). Manajeman Berbasis Sekolah Konsep, Strategi, dan Implementasi. Bandung: PT Remaja Rosdakarya.

Mustari, M. (2015). Manajemen Pendidikan. Jakarta: PT RajaGrafindo Persada.

Priyanto, D. (2014). SPSS 22 Pengolah Data Terpraktis. Yogyakarta: Andi Offset.

Purwanto. (2015). Metodologi Penelitian Kuantitatif untuk Psikologi dan Pendidikan. Yogyakarta: Pustaka Pelajar.

Rahyubi, H. (2012). Teori-Teori Belajar dan Aplikasi Pembelajaran Motorik Deskripsi dan Tinjauan Kritis. Bandung: Nusa Media.

Sanjaya, W. (2009). Strategi Pembelajaran Berorientasi Standar Proses Pendidikan. Jakarta: Kencana Prenada Media.

Sardiman, A. (2018). Interaksi dan Motivasi Belajar Mengajar. Depok: PT RajaGrafindo Persada.

Siregar, S. (2017). Metode Penelitian Kuantitatif. Jakarta: Kencana.

Slameto. (2010). Belajar dan FaktorFaktor yang Mempengaruhinya. Jakarta: PT Rineka Cipta.

Sopiatun, P. (2010). Manajemen Belajar Berbasis Kepuasan Siswa. Jakarta: Ghalia Indonesia.

Sudarmanto, R. G. (2005). Analisis Regresi 
Linear Ganda dengan SPSS. Yogyakarta: Graha Ilmu.

Sugiyono. (2015). Metode Penelitian Pendidikan Pendekatan Kuantitatif, Kualitatif dan $R \& D$. Bandung: Alfabeta.

Sujarweni, W. (2014). Metodologi Penelitian Lengkap, Praktis dan Mudah Dipahami. Yogyakarta: PT Pustaka Baru.

Wahyuningrum, K. (2015). Pangaruh Fasilitas Belajar di Sekolah terhadap Motivasi Belajar Siswa Kelas V
Sekolah Dasar Dabin IV Kecamatan Pituruh Kabupaten Purworejo. Skripsi. FIP. Universitas Negeri Semarang.

Wicaksono, P. (2012). Pengaruh Fasilitas Belajar, Motivasi Belajar dan Minat Belajar terhadap Prestasi Belajar Siswa Kelas X SMK Muhammadiyah Prambanan. Skripsi. Fakultas Teknik. Universitas Negeri Yogyakarta

Winansih, V. (2009). Psikologi Pendidikan. Medan: La Tansa Pers. 